\title{
Nitroglycerin-induced migraine type headache: bilaterally visible temporal arteries
}

\author{
Firat Bektas • Secgin Soyuncu
}

Received: 9 April 2010 /Accepted: 11 October 2010 / Published online: 4 November 2010

(C) The Author(s) 2010. This article is published with open access at Springerlink.com

\begin{abstract}
A 37-year-old man presented to the emergency department suffering from headache, nausea and vomiting, which had started $1 \mathrm{~h}$ previously. He had been diagnosed with coronary artery disease and had been taking isosorbid5-mononitrate, aspirin and metoprolol for 3 days. His vital signs and physical and detailed neurological examinations were normal except for a new onset of bilaterally visible, palpable and pulsatile temporal arteries. We discuss how nitrates can increase the cerebral and also temporal blood flow, which can rarely be seen with the naked eye, as was observed in this patient.
\end{abstract}

Keywords Headache $\cdot$ Nitrate $\cdot$ Blood flow

\section{Case report}

A 37-year-old man presented to the emergency department (ED) suffering from a headache with nausea and vomiting which began $1 \mathrm{~h}$ prior to arrival. The headache began suddenly as a severe, sharp and gradually increasing pain over his bilateral temporal areas. He had recently been diagnosed with coronary artery disease and had been taking $40 \mathrm{mg}$ isosorbid-5-mononitrate twice daily, $300 \mathrm{mg}$ aspirin once daily and $50 \mathrm{mg}$ metoprolol once daily for the past 3 days. His vital signs

F. Bektas $(\bowtie) \cdot$ S. Soyuncu

Department of Emergency Medicine,

Akdeniz University Faculty of Medicine,

07059 Antalya, Turkey

e-mail: fbektas@akdeniz.edu.tr

S. Soyuncu

e-mail: ssoyuncu@akdeniz.edu.tr and physical exam were normal except for a new onset of bilaterally visible, palpable and pulsatile temporal arteries, shown in Figs. 1 and 2. His complaints were alleviated after IV administration of a non-steroidal antiinflammatory drug (NSAID) and metoclopramide.

Prior to discharge from the ED the diameters of both temporal arteries were measured with high-resolution Doppler ultrasonography. Right and left temporal artery diameters were 3.70 and $3.45 \mathrm{~mm}$, respectively. Two days after discharge, a follow-up phone call revealed that the

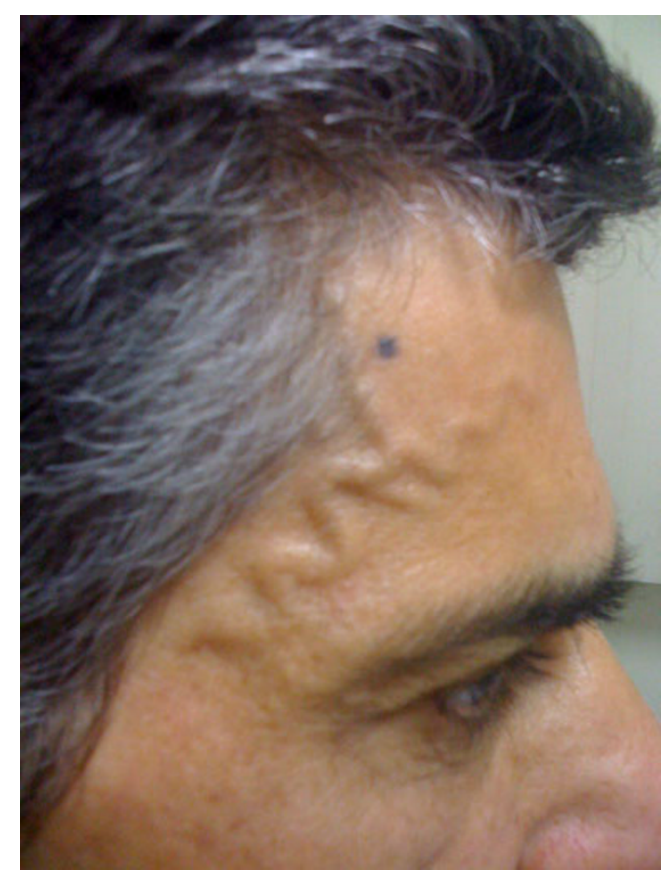

Fig. 1 Visible, palpable and pulsatile right frontal branch of the superficial temporal artery 


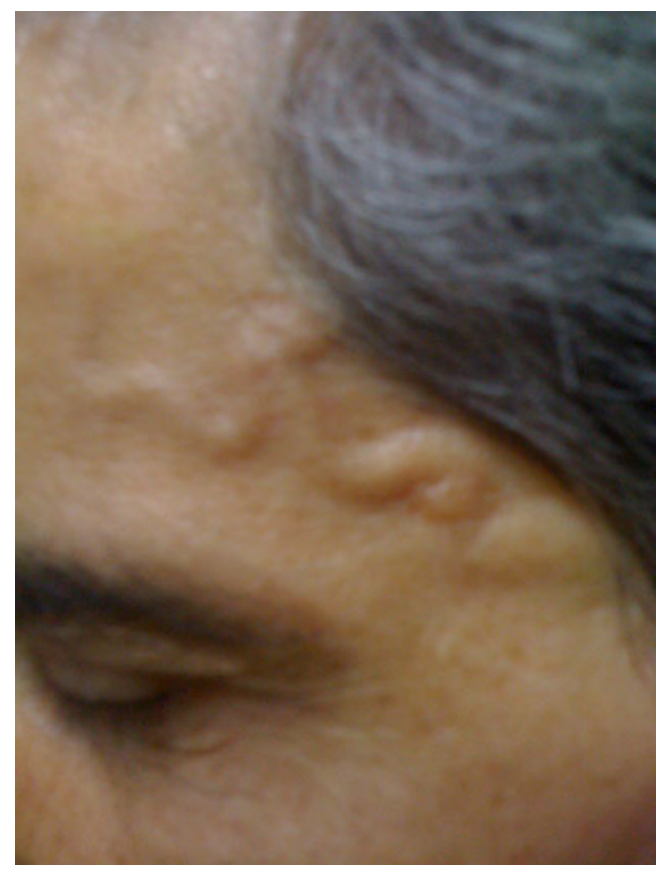

Fig. 2 Visible, palpable and pulsatile left frontal branch of the superficial temporal artery

patient's headache had not returned and that his temporal arteries were no longer visible.

\section{Discussion}

Organic nitrates are commonly used for the treatment of ischaemic heart disease. They dilate the coronary arteries and thus improve coronary blood flow. Since organic nitrates affect all smooth muscle beds, their effects extend beyond the coronary arteries. Low concentrations of nitroglycerin may result in venodilation that precedes the arteriodilation. Higher doses result in venous pooling and postural hypotension. Dilation of cerebral arteries causes the commonly reported side effect of migraine type headache [1]. However, during long-term nitrate treatment, a headache often abates over a period of time, whilst the anti-anginal effect remains, implying tolerance in the cephalic more than in coronary arteries [2]. Organic nitrates induce headache via release of nitric oxide, a potent regulator of vascular tone [3]. The release of nitric oxide stimulates soluble guanylate cyclase, causing increased cyclic guanylate monophosphate (cGMP). Increased cGMP activates cGMP-dependent protein kinase, culminating in dephosphorylation of the myosin light chain and subsequent vascular smooth muscle relaxation and vasodilation [4]. As a result of these actions, nitrates increase the cerebral blood flow and provoke a vascular type headache in healthy subjects.

Acknowledgements This case was supported by Akdeniz University Research Foundation.

\section{Conflicts of interest None.}

Open Access This article is distributed under the terms of the Creative Commons Attribution Noncommercial License which permits any noncommercial use, distribution, and reproduction in any medium, provided the original author(s) and source are credited.

\section{References}

1. Moncada S, Higgs EA (1991) Endogenous nitric oxide: physiology, pathology and clinical relevance. Eur J Clin Invest 21(4):361-374

2. Fletcher A, Bulpitt CJ (1988) Quality of life on angina therapy. Lancet 2(8617):959

3. Ohar JM, Fowler AA, Selhorst JB, Glauser FL (1985) Intravenous nitroglycerin-induced intracranial hypertension. Crit Care Med 13 (10):867-868

4. Kitazawa T, Semba S, Huh YH, Kitazawa K, Eto M (2009) Nitric oxide-induced biphasic mechanism of vascular relaxation via dephosphorylation of CPI-17 and MYPT1. J Physiol 587(Pt 14):3587-3603 